\title{
TEACHING SELVES: IDENTITY, PEDAGOGY, AND TEACHER EDUCATION
}

\author{
Jane Danielewicz \\ State University of New York Press, 2001 \\ Pham Hai Yen* \\ Haiphong University, Phan Dang Luu, Kien An, Haiphong, Vietnam
}
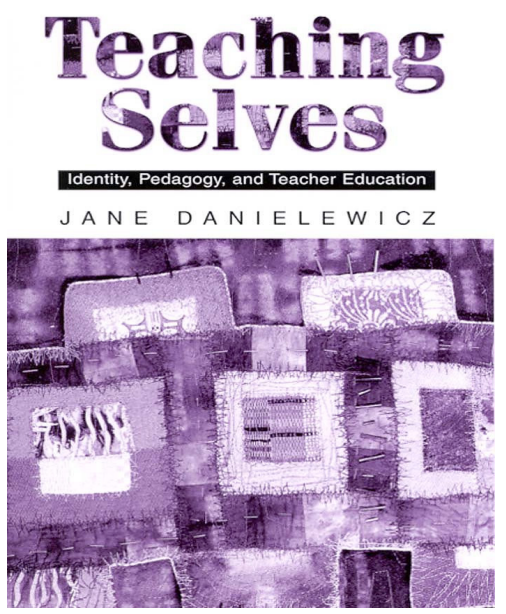

\section{Core contents of the book}

Teaching Selves by Jane Danielewicz is a book about how identities, the word referring to how individuals know and name themselves and how they are recognized and regarded by others, arise and the issue of becoming - the process of how a person becomes someone, particularly of how students become teachers. In it, the author, who works in teaching teachers, proposed pedagogy for identity development - the process of becoming basing on her belief that

* Tel.: 84-1225357669

Email: phamhaiyen.dhhp@gmail.com
"What makes someone a good teacher is not methodology, or even ideology. It requires engagement with identity, the way individuals conceive of themselves so that teaching is a state of being, not merely ways of acting or behaving." Besides, she described the qualities that must characterize the author and her colleague's teaching so that the students they encounter become something other than students as they believe that education is about growth and transformation, not only of culture, but of persons too. Concentrating on identity, the stories of six undergraduate students enrolled in a secondary teacher education program at a large state university 
were told. The author applied a qualitative method with interviews, observations, and teaching experiences with the subjects over a three-year period to explore the process of becoming a teacher, focusing on the influences of education courses and other characteristics of the teacher education program. This is a paperback text consisting of seven chapters. Chapter one looks at identity and pedagogy, Chapter two mentions aspiring teachers, Chapter three explores them seeing themselves as teachers, Chapter four investigates selves at the boundaries, Chapter five clarifies practicing teachers, Chapter six presents a pedagogy for identity development and Chapter seven highlights teaching selves. The results of analysis are backed up with the reflections at the end of each chapter.

Chapter one - Identity and Pedagogy - consists of the following parts: Getting ready, Insisting on Identity, Defining identity, The role of discourse, The secondary teacher education program, The idea of pedagogy, Proposing a pedagogy and Reflection. All the contents expressed the author's experiences that she had got from the real teaching practice as well as her knowledge and perspectives of some theoretical issues such as identity, discourse and pedagogy.

Stating her self's experiences in training teachers, the author drew many experiential lessons on how to become a good teacher and how to educate teachers. Take page 9 for example, the author claimed that "becoming a teacher means that an individual must adopt an identity as such. I take this strong position — insisting on identity — because the process of teaching, at once so complicated and deep, involves the self." To do that, she advises the students who are trained to become teachers to develop personal theories of action - how they might act if they were teachers. This has several benefits. "First, the students can realize that teaching is complicated and that it is a generative process. Second, they are able to feel how theory and practice are yoked together. Without much effort, they can see why they must link the methods they adapt to their beliefs. Finally, proposing theories of action forces students to integrate the whole range of variables involved in any teaching situation rather than operating from one perspective alone."

Besides, the authors' points of view in the term "identity" and the relationship between identity development and discourse were analyzed. To begin with, identity is defined as our understanding of "who we are" and of "who we think other people are". Reciprocally, it also comprises "other people's understanding of themselves and others (which includes us)". Theoretically, there are two notions involved in the concept of identity: similarity and difference. So identities function as the ways we relate to and distinguish individuals (and groups) in their social relations with other individuals or groups. In terms of characteristics, she wrote: "identities can never be unified or fixed; they are always influx, always multiple and continually under construction. Yet this doesn't mean that selves don't exist or are unrecognizable; there are moments and conditions of coalescence." In terms of the way of forming, identity has dependent relationship with discourses. According to the author, individuals' identities are produced through participation in discourse. To be more specific, identities are the result of dynamic interplay between discursive processes that are internal (to the individual) and external (involving everyone else). In terms of dimensions, the author followed Jenkins (1996)'s theory which mentioned two main dimensions of 
the concept of identity, one aspect having to do with a single person - individual identity and the other with groups - collective identity. Having clarified the above theoretical issues, the author pronounced her scope of the study: "describing the identity development of the students who are the center of this book, I will show how certain contexts and practices (for instance, composing a philosophy of teaching) promote the individual dimension while other situations and persons (for instance, the teaching practicum) contributes to the collective aspect of a teaching identity." (p.12)

For pedagogy, the chapter presents the author's idea and proposal. Firstly, "the best pedagogy gets its shape and force from its theoretical roots" which means a teacher applies her knowledge into practice basing on the material conditions and needs of her students, and then begins the cycle of reflection and reconception. Thus, teaching is supposed to be an act that once started is never over. Secondly, with both evidence and testimony from six participants in the study, the writer gives a proposal that describes a set of principles (ten in all) that, taken together, constitute pedagogy for identity construction. The principles include discourse richness and openness, dialogue and a dialogic curriculum, collaboration, deliberation, reflexivity, theorizing in practice, agency, recursive, representation, authority, and enactment. All principles depend on the theoretical notion that selves and identities are constructed by discourses themselves and everyday discursive practices.

Chapter two - Aspiring Teachers - is written about the contents: A Teacher's Past, Newcomer, Six Students, Positions and Reflections. They are about the author self and her six students' stories that help her come to some conclusions of identity construction.
First of all, "participating in multiple discourses, as we all do simultaneously, (on the streets, in classrooms, at home, in churches) alters not only the individual but also the social communities within which we are always situated." Secondly, "in the everconstant process of identity construction, it is the ways that we are like and unlike others that make and mark our identities as individuals". Thirdly, the students' existing identities shaped by the social class background and economic conditions of their families affect, influence, interact with, and often conflict with an individual's attempt to become a teacher, to develop a professional identity. Last but not least, the author mentioned the role of positions in constructing identity pointed out by Stuart Hall (1997): "it is how we are represented by the positions we adopt (or are forced to adopt) at different times and places, and the social roles we play in each varying circumstance, that make us (momentarily) who we are." (p.32)

Chapter three - Seeing Themselves as Teachers - reveals how the different positions each student occupies at any one time and place forms the path and journey each takes toward becoming a teacher through the parts named: Explaining Selves, Why Teach?, What Kind of Teacher? and Reflections. Through analyzing the students' answers to the question "How did you decide to be a teacher?", the dialectical process by which identity positions are achieved was revealed. The themes drawn for it are Always known, Difference between feeling and being, Role models, Teaching as service, Loving English, Altruism, Saving grace, A calling or ... a job. The chapter also explores each student's idea as they anticipate being teacher interns, a hybrid position existing on the cusp between being known as students and/ or as teachers. More specifically, the students with ideas are: Michaela: identifying with and 
beyond her mentor teacher; Donna: Sharing with her mentor the goal to center instruction on students; Lauren: Being a teacher depends on other people's perceptions; Rick: Identity commitments are rooted in prior experience; Elizabeth: Developing identity depends on seeing a place for yourself; Howard: Being a good teacher depends on the freedom to do something different.

Chapter four - Selves at the Boundaries - with subtitles as Two Stories of Becoming, Elizabeth's Story, Rick's Story, focuses on two students, Elizabeth and Rick, and tells their stories in more depth to demonstrate how variable identity processes are. The stories demonstrate how selves are fluid and ever changing, labile and mutable, responsive to the forces of inner desires and outer conditions. The stories provided the evidence for the author's conclusion that identities are momentary, almost ephemeral and "boundaries of the self" - a metaphor - presumes a stability that is nonexistent. Additionally, she supposed the variability, intensity, and richness of the experience was significant to Elizabeth and Rich's development as people. Then she concluded, "Without worrying too much about uniformity or regulation, we as teacher educators can try to provide fertile, changeable, and challenging environments both in our classrooms at the university and in public school contexts that invite and engage students in the dynamic process of becoming teachers."

Chapter five - Practicing Teachers, divided into smaller parts as Crossing Boundaries, Unpredictable and Reflection, focuses on the development of collective identity - being recognized by others as a teacher - through interactions between interns and mentor teachers in an actual school context. The interns' collective identities, then, are contingent on two things: their being involved in actual teaching situation with a professional teacher, and their affiliation with mentor. The word affiliation refers to a relationship not only between individuals, which suggests some form of association, alliance, union, or connection, but also between institutions and individuals. Affiliations can have negative or positive valences, may exist when power differentials are slight or imbalanced, and can range from weak to strong. The stories in this chapter show that institutions do affect the development of individuals' collective identity. To be more specific, there are eight affections identified: Affiliation through identification, Affiliation through differentiation, Performing the role in a substantive manner, Joint problem solving in a local context, Oppositional affiliation, Disharmony between individual and group identity, Institutions act upon identities, Identities develop concurrently. The stories of the students in this chapter confirm the evolving nature of collective identity formation, demonstrating how such identities are "flexible, situational and negotiable" (Jenkins, 1996: 102).

Chapter six - A Pedagogy for Identity Development, about the contents entitled The Second Paragraph Must Have Eight, Pedagogy, Discourse, The Literacy Course, Principles of Pedagogy, Principles, Reflections, proposes and provides detailed explanation of ten pedagogy principles introduced in chapter one. Five of them are structural principles which refers to the way the social environment of the classroom is structured, designed or arranged, as well as to the nature of interactions that occur there. The others are performative principles that refer to individuals and their actions or performances as well as to the implications of action in particular social settings. Figure 1 below outlines the classification of these principles as well as extracts some key words that each principle refers to for helping to define them. 


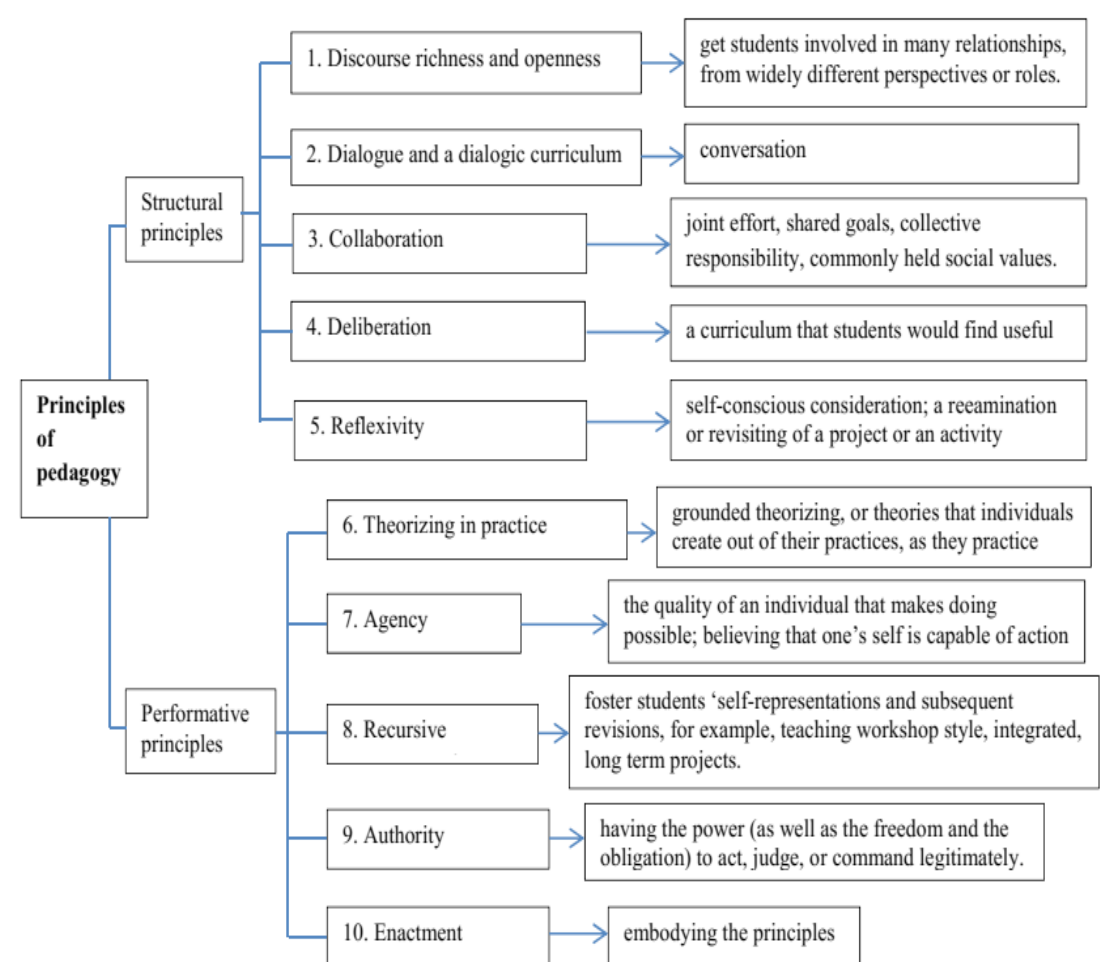

Figure 1. Principles of pedagogy by Jane Danielewicz (2001: 139-175)

In Chapter seven - Teaching selves, with the subdivisions called Process and Patience, Failure, Six Students a Year or So After Graduation, A Few Necessities, Principles (One Last Time), Reflections, some more meaningful ideas for teaching identity can be found. Firstly, it defines a process teacher as one who teaches students a process - how to be a teacher - by engaging them in a process - learning to be a teacher. For this job, patience is necessary because identities themselves are always unfinished and in the making; identities develop through continuous processes. More noticeably, the author suggested that the ideal teacher education program should be: active, holistic and integrated, embedded in a discourse community, rich in relations, and morally engaged.

\section{Values of the book}

There are several values brought by the book among which theoretical and applicable values are the most prominent.
Theoretically, the book is not only a qualitative research that contributes to widening knowledge and experiences in doing research on teacher identity, especially with the authors' definition of teacher identity, analysis of the relationship between identity and discourse and her applying research techniques and doing qualitative analysis, but also a meticulous study whose results have enriched the educational literature, especially with her point of view that education is about growth and transformation, and a rather great amount of pedagogical principles drawn from the study.

Firstly, the author's definition of teachers' professional identity as she wrote: "I regard "becoming a teacher" as an identity forming process whereby individuals define themselves and are viewed by others as teachers" (p.3) shares the common views with other writers during the period 1988-2000. For example, Beijaard, 
Meijer and Verloop (2004) found out, "Most of the researchers saw professional identity as an ongoing process of integration of the 'personal' and the 'professional' sides of becoming and being a teacher." (p.113). This contributes to the insistence in understanding the term "teacher identity", an abtract issue, in research work, which is really useful for the beginners in this field when there are a lot of different ways of defining it, as seen in Table 1 - Overview of the studies on professional identity formation (p.110) by Beijaard, Meijer and Verloop (2004).

Secondly, identifying "identities are produced through participation in discourse" (p.11), the author wrote, "I am acutely selfconscious that discourse is simultaneously a set of practices to be taught, a medium of instruction, and the very material substance out of which identities arise." Exploring a pedagogy and a teaching program basing on this relationship between identity and discourse opens a noticeable and unique approach in studying teacher identity formation. This can be considered a novel idea which meets the science's demand because it can help to fill the gap in the store of knowledge of teachers' professional identity. Beijaard, Meijer and Verloop (2004) confirmed, "It is argued that, in future research on teachers' professional identity, more attention needs to be paid to the relationship between relevant concepts like 'self' and 'identity', the role of the context in professional identity formation, what counts as 'professional' in professional identity, and research perspectives other than the cognitive one that may also play a role in designing research on teachers' professional identity."

Thirdly, the study can be admirable for the thickness of longitudinal data which is an essential criterion for qualitative analysis. This characteristic was identified by Wolcott (1999): "It is longitudinal in nature, allowing you as the researcher to observe and record changes over time" and by Nunan (1992) "Longitudinal: The research is relatively long-term". The book is a rich collection of the authentic stories from the participants and the author herself, which provides a solid foundation for the arguments and themes that emerged through the telling of these stories. Thus, the readers will be convinced with the results and recommendation of the study. The authors' way and skill of collecting data in the book should be considered a lesson for other researchers, especially the novice ones.

Apart from these merits, in my opinion, the most important theoretical value of the book is ten principles of pedagogy, the main result of the research, which is presented in figure 1. Among them, the structural principles describe general properties that should characterize the curriculum, shape the classroom environment, and inform the teacher's approach to course design and methods. In contrast, performative principles concern what individuals do, focus on persons as actors and on the drama of social interaction among them. I totally agree with the author that these pedagogical principles are not directives; rather, they are characteristics of the learning environment and philosophical lenses through which teachers can look. In this sense, the principles offer a kind of pragmatic theory; they describe an approach, a disposition, a sensibility, or a temperament toward teaching. Besides, backing up the point of view that education is about growth and transformation, the book introduced her training program and her learners' reflections on it, which widens readers' knowledge on teacher training job.

In terms of application, teachers and administrators working in teacher education would enjoy the stories which are rich real experiences and it is important we document these. By reading the book, they can draw out 
different points relating to the experiences of the educators and administrators. Both graduate and undergraduate students studying teacher education would find this a useful text. They have a lot to learn from the stories and the principles of pedagogy provided in the book to build their teacher identity and to do a good job in becoming a teacher. For researchers, the book provides not only theoretical background but also suggestion for further research. Take Alsup J. (2005) for example, she mentioned this book when defining 'the border land' and gain some lessons from the strong and weak points of the point of view that "education is about growth and transformation, not only of culture, but of persons too" (p.1) and the principles of pedagogy proposed by 'Teaching selves'.
Briefly, Teaching selves is a book of value in both theory and practice. People who work in education would get valuable lessons from it.

\section{References}

Alsup, J. (2005). Teacher Identity Discoursel Negotiating Personal and Professional Spaces. Urbana, IL: NCTE-Routledge Research Series.

Danielewicz, J. (2001). Teaching selves: identity, pedagogy, and teacher education. Albany, NY: State University of New York Press.

Douwe Beijaard*, Paulien C. Meijer, Nico Verloop (2004). Reconsidering research on teachers' professional identity. The Netherlands: Teaching and Teacher Education.

Nunan, D. (1992). Research methods in language learning. Cambridge: Cambridge University Press.

Wolcott, H. F. (1999). Ethnography: A way of seeing. Walnut Creek, CA: Altamira Press.

\section{THE AUTHOR}

Jane Danielewicz is Associate Professor, Associate Director of the UNC Writing Program and also involved in designing courses and teaching for the University Honors Program. From 20082011, she was the primary investigator for a Spencer-Teagle Foundations Grant for Improvement of Undergraduate Education at Research Universities, which emphasized writing and research (with Professor Pat Pukkila, Director, UNC Office for Undergraduate Research and Dean Bobbi Owen, UNC Office for Undergraduate Education). She is currently a co-primary investigator for a CCCC Research Initiative Grant to support research on the genres being assigned in firstyear writing and in undergraduate courses across disciplines (with Professor Jordynn Jack, co-PI, 2014-2016). 